\title{
New MRI Studies Support the Blanchard Typology of Male-to-Female Transsexualism
}

\author{
James M. Cantor
}

Published online: 8 July 2011

(C) The Author(s) 2011. This article is published with open access at Springerlink.com

Two independent empirical articles have recently appeared in the literature that, taken together, bear out an hypothesis Blanchard (2008) postulated in the Archives about brain development in transsexualism:

[T]he brains of both homosexual and heterosexual maleto-female transsexuals probably differ from the brains of typical heterosexual men, but in different ways. In homosexual male-to-female transsexuals, the difference does involve sex-dimorphic structures, and the nature of the difference is a shift in the female-typical direction. If there is any neuroanatomic intersexuality, it is in the homosexual group. In heterosexual male-to-female transsexuals, the difference may not involve sex-dimorphic structures at all, and the nature of the structural difference is not necessarily along the male-female dimension. (p. 437)

Blanchard's prediction follows from studies that have repeatedly shown that the homosexual male-to-female transsexuals are "female-shifted" in multiple, sexually dimorphic characteristics, whereas the heterosexual male-to-female transsexuals are not (Blanchard, 1989a, 1989b). For example, homosexual maleto-female transsexuals are sexually attracted to natal males, express greater interest in female-typical activities (even in childhood), and are naturally effeminate in mannerism. In contrast, heterosexual male-to-female transsexuals are indistinguishable from nontranssexual natal males on these variables. The heterosexual transsexuals are still distinct from typical males in other ways, however, such as by manifesting "autogynephilia"- the erotic interest in or sexual arousal in response to being or seeming female. The consistent detection of cross-sex features among

J. M. Cantor ( $\square)$

Law and Mental Health Program, Centre for Addiction and Mental

Health, 250 College St., Toronto, ON M5T 1R8, Canada

e-mail: James_Cantor@camh.net homosexual male-to-female transsexuals, but not among heterosexual male-to-female transsexuals, led Blanchard to predict that the cross-sex pattern would also emerge at the level of brain anatomy and be limited to the homosexual male-to-female transsexuals. That prediction now appears to be the case, with Rametti et al. (2010) supporting his prediction for the homosexual transsexuals, and Savic and Arver (2010), for the heterosexual transsexuals.

The Rametti team used an MRI technique called Diffusion Tensor Imaging to compare homosexual male-to-female transsexuals $(n=18)$ with nontranssexual, heterosexual control males $(n=19)$ and with nontranssexual, heterosexual control females $(n=19)$. They contrasted the male controls with the female controls to identify the sex-dimorphic portions of the brain and then contrasted the homosexual transsexuals with each of the control groups on the dimorphic brain regions so identified. The initial contrasts identified six sex-dimorphic brain regions. The homosexual transsexual sample was intermediate in volume on all six brain structures, significantly different from the male controls on five of the six (and significantly different from the female controls on all six). That is, these male-to-female transsexuals were different from the control males, shifted towards the female direction on all parameters.

Savic and Arver (2010) applied anatomical MRIs with an analogous research design, identifying the sex-dimorphic portions of the brain and contrasting the (this time) heterosexual transsexual sample $(n=24)$ with each control sample ( $n$ 's $=$ 24 each) on the sex-dimorphic brain regions. Of the eight brain regions that distinguished male from female brains, the heterosexual transsexual sample differed from the male controls on none (Savic \& Arver, 2010, Table 3). Of the four brain regions that distinguished these heterosexual transsexuals from the male controls, sex-dimorphism was present in none (Savic \& Arver, 2010, Table 3). As Savic and Arver themselves emphasized, "Contrary to the primary hypothesis, no sex-atypical 
features with signs of 'feminization' were detected in the transsexual group.... The present study does not support the dogma that [male-to-female transsexuals] have atypical sex dimorphism in the brain" although that statement should have been restricted to refer to heterosexual male-to-female transsexuals only.

Also meriting emphasis is that - although these data disconfirm that the heterosexual type has a feminized brain patternthe data nonetheless confirm that heterosexual transsexuals have a brain structure distinct from that of typical (nontranssexual) persons. Their gender identity is not a transient or ephemeral characteristic, but a likely innate and immutable characteristic, emerging from their particular brain structure.

Open Access This article is distributed under the terms of the Creative Commons Attribution Noncommercial License which permits any noncommercial use, distribution, and reproduction in any medium, provided the original author(s) and source are credited.

\section{References}

Blanchard, R. (1989a). The classification and labeling of nonhomosexual gender dysphorias. Archives of Sexual Behavior, 18, 315-334.

Blanchard, R. (1989b). The concept of autogynephilia and the typology of male gender dysphoria. Journal of Nervous and Mental Disease, $177,616-623$.

Blanchard, R. (2008). Deconstructing the Feminine Essence Narrative. Archives of Sexual Behavior, 37, 434-438.

Rametti, G., Carrillo, B., Gómez-Gil, E., Junque, C., Zubiarre-Elorza, L., Segovia, S.,... Guillamon, A. (2010). The microstructure of white matter in male to female transsexuals before cross-sex hormonal treatment: A DTI study. Journal of Psychiatric Research. doi:10.1016/ j.jpsychires.2010.11.007.

Savic, I., \& Arver, S. (2010). Sex dimorphism of the brain in male-tofemale transsexuals. Cerebral Cortex. doi:10.1093/cercor/bhr032. 